ISSN 2179-345X

Licenciado sob uma Licença Creative Commons

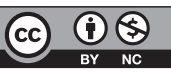

\title{
A sustentabilidade de produtos e serviços enquanto pré-requisito ao consumo consciente ${ }^{1}$
}

\author{
Sustainability of products and services as a \\ prerequisite to the conscious consumer
}

\section{Jailson de Souza Araújo ${ }^{[a]}$, Karlo Messa Vettorazzi ${ }^{[b]}$}

[a] Advogado, Mestrando em Direito Socioambiental pela Pontifícia Universidade Católica do Paraná (PUCPR), professor da Faculdade Internacional de Curitiba das cadeiras de Fundamentos de Direito, Direito Comercial e Societário, Legislação Social e Trabalhista e do Núcleo de Prática Jurídica Cível, Curitiba, PR - Brasil, e-mail: araujoad@yahoo.com.br

[b] Advogado, Mestrando em Direito Socioambiental pela Pontifícia Universidade Católica do Paraná (PUCPR), professor da Faculdade de Ciências Sociais de Cascavel, PR, das cadeiras de Direito Processual Civil, Direito Civil II - Obrigações e Direito Ambiental e Agrário e professor do Centro Universitário Franciscano da cadeira de Processo Civil (UNIFAE), Curitiba, PR - Brasil, e-mail: karlovettorazzi@hotmail.com

\section{Resumo}

A relação entre consumo e meio ambiente é intrínseca, pois tudo o que consumimos, de uma forma ou outra, provêm de recursos naturais ou a partir da utilização destes. $\mathrm{O}$ ato de

1 Trabalho apresentado no Simpósio "Sociedade de Informação", realizado nas dependências da PUCPR, no âmbito do PROCAD/CAPES (UFSC, PUCPR, UNIBRASIL e UNISANTOS) Sociedade de Informação: democracia, desenvolvimento e inclusão tecnológica. 
consumir é inerente à natureza humana; consumir é fazer parte da cadeia trófica e consequentemente significa depender da natureza. Neste sentido, a proliferação de novas tecnologias gera novas formas de trabalho e, em consequência, novas formas de consumo. Esta cadeia, por sua vez, produz mudanças na sociedade, no consumo e na natureza, transformando, por fim, os objetos em bens de consumo e, paralelamente, cria novos problemas ambientais. Assim, os problemas ambientais causados pelo homem decorreram, sobretudo, do modo como as sociedades se apropriaram, usaram, destinaram e transformaram os recursos naturais. A natureza não deve ser intocável, pois ela nos ajuda a enfrentar os desafios da mudança social, para dar às pessoas que vivem em estado de miséria uma condição mais digna. Todavia, isso não pode ser feito sobre bases de "crescimento a qualquer preço", pois o meio ambiente precisa ser considerado. Talvez a mais eficiente solução para reversão deste cenário seja a educação ambiental do consumidor para o exercício do consumo consciente, enquanto agente socialmente responsável em defesa do desenvolvimento e do crescimento sustentável.

Palavras-chave: Educação ambiental. Direito à informação. Consumo consciente. Sustentabilidade ambiental.

\begin{abstract}
The relationship between consumption and the environment is intrinsic, because everything we consume, in one form or another, come from natural resources or through the use of them. The act of consuming is inherent to human nature; to consume is to be part of the food chain and therefore depend on the nature means. In this sense, the proliferation of new technologies generates new forms of work and as a result new forms of consumption. This chain, in turn, produces changes in society, consumption and nature, transforming, finally, the objects of consumer goods and, in parallel, creating new environmental problems. Thus, the environmental prob-lems caused by man due especially to the way societies are appropriated, used, transformed and allocated resources. Nature must not be untouchable, because it helps us meet the challenges of social change, to give people living in a state of misery a condition more worthy. However, this can not be done on basis of "growth at any price" because the environment needs to be considered. Perhaps the most efficient solution to reverse this scenario is the environmental education of the consumer to exercise the conscious consumer, as an agent in defense of the socially responsible development and sustainable growth.
\end{abstract}

Keywords: Environmental Education Right to Information. Conscious consumption. Environmental sustainability. 


\section{Introdução}

Após a Segunda Guerra Mundial, os Estados Unidos contavam com capacidade industrial excedente, mão de obra disponível e uma economia estagnada. Na Europa, a crise era generalizada. A solução planejada diante da crise no contexto macroeconômico mundial foi a produção em larga escala de bens de consumo, de forma a reaquecer a economia e gerar emprego e renda.

Neste processo, iniciou-se a utilização de recursos naturais sem estabelecer, enquanto prioridade, uma preocupação com o impacto ambiental gerado ou mesmo analisar o ciclo de vida completo dos produtos e serviços disponibilizados para consumo e suas consequências para o meio ambiente. Neste contexto, recursos naturais foram maciçamente utilizados como se fossem inesgotáveis. A justificativa era a necessidade do restabelecimento da economia e a promoção do bem-estar da população.

Hoje, vivemos um cenário de relativa estabilidade global. O modelo capitalista prevaleceu com a queda do muro de Berlim em 1989 e a globalização é uma realidade não exclusivamente econômica, em que pese este ser seu aspecto mais expressivo, inclusive no que se refere à pressão e acentuado estímulo ao consumo e ao consumismo, este enquanto modalidade nociva de consumo.

Esse modelo de consumo vem causando nas últimas décadas um expressivo dano ambiental - em alguns casos, danos irreversíveis. Suas consequências diretas e indiretas (extinção de espécies, mudanças climáticas, diminuição das calotas polares, etc.) têm despertado a preocupação de uma parcela significativa da sociedade para a urgente necessidade de mudança do modelo de exploração dos recursos naturais, de forma a suprir as necessidades humanas de forma equilibrada e sustentável, conciliando o desenvolvimento econômico, o bem-estar coletivo e a indispensável preservação do meio ambiente.

A mudança desse cenário depende de um novo modelo de desenvolvimento a ser adotado pelo Estado, pelos fornecedores e pelos consumidores. E considerando a gravidade do problema a ser enfrentado, não é 
razoável esperar que o Estado sozinho seja capaz de resolver o problema e ofertar a solução ideal.

Sem dúvida, é dever do Estado implementar políticas públicas que assegurem a efetividade do cumprimento da defesa do meio ambiente, bem-estar social e da defesa dos direitos difusos, conforme determina a Constituição Federal de 1988. Entretanto, é também dever da iniciativa privada, a partir de uma nova postura dos fornecedores, que devem adotar políticas empresariais de responsabilidade socioambiental, e principalmente dever do cidadão-consumidor, que, por intermédio da educação ambiental desde os primeiros anos de vida (idade em que o ser humano está mais suscetível a absorver informação e moldar seu comportamento), deverá criar uma nova mentalidade, despertando consciência para a necessidade do consumo consciente, sempre em respeito à preservação ambiental, adotando postura responsável, consumindo de forma a causar o menor impacto possível ao meio ambiente, e que o ciclo de vida do produto ou serviço adquirido respeite, acima de tudo, a sustentabilidade ambiental.

O consumidor-cidadão é uma peça-chave na solução do problema que ora se apresenta, mas para que seu papel possa ser exercido de forma consciente e plena, faz-se necessária a existência de duas premissas: a educação e consciência ambiental e o acesso à informação ambientalmente qualificada, de maneira que tal informação lhe permita exercer de forma plena seu direito de escolha, optando por consumir produtos e serviços cuja origem seja de fornecedores socioambientalmente responsáveis.

\section{Desenvolvimento}

Em 1992, os olhos do mundo voltaram-se ao Brasil para discutir o meio ambiente e o desenvolvimento sustentável na Conferência das Nações Unidas para o Meio Ambiente e o Desenvolvimento, realizada entre 3 e 14 de junho de 1992 no Rio de Janeiro, contando com representantes de 178 países. Na oportunidade, discutiu-se a respeito da poluição do ar, da água, do solo, da pobreza, desigualdade social, superpopulação nas 
periferias dos grandes centros urbanos, enfim, dos graves problemas ambientais enfrentados pela população mundial.

Durante a conferência, elaborou-se um documento intitulado Agenda 21, que é um programa de ação que viabiliza novo modelo de desenvolvimento ambientalmente racional, conciliando métodos de proteção ambiental, justiça social e eficiência econômica.

Para Liliana Angel Vargas (2005), em relação à educação ambiental, no capítulo 36 da Agenda 21, intitulado "Promoção do ensino, da conscientização pública e do treinamento", ressalta-se a importância da reorientação do ensino, tanto formal como informal, para que sirva como apoio aos pressupostos e objetivos do desenvolvimento sustentável.

\section{O imperativo da educação ambiental em defesa da sustentabilidade ambiental e como fator de estímulo ao consumo consciente}

O consumidor brasileiro consciente espera um comportamento ético das empresas que lhe ofertam produtos e serviços. E para o exercício pleno de seu direito de escolha, demanda informações a respeito das práticas empresariais relacionadas à responsabilidade socioambiental, rejeitando, por consequente, ofertas decorrentes de empresas que utilizem propaganda enganosa ou abusiva, que não respeitem as normas de preservação ambiental (principalmente no que se refere à poluição e à degradação), prestigiando ofertas realizadas por empresas que adotem políticas sérias de preservação ambiental, de respeito ao consumidor, à comunidade na qual a empresa está inserida e ao meio ambiente.

Entretanto, a escolha consciente demanda um preparo intelectual do consumidor cidadão. E tal preparo deve se iniciar com a educação ambiental de base, por meio de uma nova abordagem no estudo das disciplinas tradicionais (ao invés de simplesmente inserir no currículo escolar uma disciplina estanque intitulada Educação Ambiental ou algo semelhante, com o que discordamos), em que se contextualize o estudo do meio ambiente e o impacto causado pelo ser humano nas mais diversas 
áreas do conhecimento, sendo o respeito pelo meio ambiente e a promoção de práticas sustentáveis um vetor a ser debatido diuturnamente no ensino fundamental, médio e superior, inclusive como forma de preparar a futura geração de formadores de opinião e líderes.

O que se pretende com a mudança do atual modelo de educação é que ele sirva não apenas para a formação de consumidores ambientalmente responsáveis, mas também como ponto de partida para a ação transformadora que se faz necessária, de forma a propiciar o resgate de valores sociais como a ética, o senso de integração à natureza, solidariedade, qualidade de vida, promoção da justiça social e da dignidade da pessoa humana.

Neste sentido, dentre as iniciativas tomadas pelo poder público, destacamos a criação do Departamento de Educação Ambiental em 1999, vinculado ao Ministério do Meio Ambiente (MMA), com propósito de desenvolver ações a partir das diretrizes definidas pela Lei 9.795/99, que estabelece a Política Nacional de Educação Ambiental. A regulamentação da Lei 9.795/99 define que a coordenação da Política Nacional de Educação ficará a cargo de um órgão gestor dirigido pelos ministros de Estado do Meio Ambiente e da Educação. De acordo com o Ministério do Meio Ambiente, ${ }^{2}$ a missão do Departamento é "estimular a ampliação e o aprofundamento da educação ambiental em todos os municípios e setores do país, contribuindo para a construção de territórios sustentáveis e pessoas atuantes e felizes".

De acordo com art. $1^{\circ}$ da Lei 9.795, de abril de 1999,

entende-se por educação ambiental os processos por meio dos quais o indivíduo e a coletividade constroem valores sociais, conhecimentos, habilidades, atitudes e competências voltadas para a conservação do meio ambiente, bem de uso comum do povo, essencial à sadia qualidade de vida e sua sustentabilidade.

2 Disponível em: <http://www.mma.gov.br/index.php?ido=conteudo.monta\&idEstrutura=20>. Acesso em: 17 jun. 2008. 
Complementando a educação de base, inclusive para atingir a parcela da sociedade que não mais frequenta os bancos escolares e acadêmicos, é salutar que o Estado incentive iniciativas privadas que visem à educação ambiental fora do âmbito escolar, a partir de medidas informais de educação ambiental, por meio de ações pontuais e com abordagens e métodos flexíveis, de forma a atingir públicos variados, inclusive em locais públicos. Podemos citar como exemplo as campanhas promovidas por empresas privadas e pelo Terceiro Setor (utilização de sacolas reutilizáveis, economia de energia e água, reciclagem, escolha de produtos com certificação ambiental, dentre outras iniciativas).

Não há dúvida de que a educação é a melhor ferramenta para a preservação do meio ambiente. É premissa obrigatória para o despertar da consciência para a necessidade e importância da preservação do meio ambiente. E por meio dela, o cidadão consumidor terá condições de perceber que suas atitudes e hábitos de consumo geram repercussões ambientais, podendo exercer sua cidadania responsável ao adotar e disseminar práticas que minimizem o impacto ambiental, principalmente no que se refere aos hábitos de consumo, que certamente será consciente e solidário.

Estatisticamente, o aumento do interesse do cidadão em consumir de forma consciente e sustentável pode ser percebido inclusive a partir de estudos específicos, como o realizado pelo Instituto Akatu - pelo consumo consciente, intitulado "Descobrindo o consumidor consciente", ${ }^{3}$ que evidenciou que $94 \%$ da população ouvida na pesquisa declarou que "as empresas deveriam se preocupar mais com o meio ambiente"; $91 \%$ das pessoas ouvidas afirmaram que "as empresas devem ir além do exigido pela lei para ajudar a construir uma sociedade melhor"; $72 \%$ das pessoas que responderam o estudo afirmaram que pagariam mais por um produto ou serviço desde que a empresa realizasse projetos em favor do meio ambiente, e $70 \%$ pagariam mais pelo produto desde que ele fosse inofensivo ao meio ambiente (INSTITUTO AKATU, 2008).

3 Disponível em: <http://www.ethos.org.br/_Uniethos/Documents/Conclusoes_Akatu.pdf>. Acesso em: 15 jun. 2008. 
O estudo demonstra que o consumidor percebe a necessidade da mudança de seus hábitos de consumo, e no exercício de sua cidadania, demonstra estar disposto a aceitar novos padrões de comportamento, inclusive nas suas decisões de compra e relações com empresas fornecedoras de produtos e serviços, em prol da defesa do meio ambiente, das futuras gerações e de bem desempenhar seu papel, enquanto indivíduo consciente, em benefício da coletividade.

Entretanto, o consumidor-cidadão, ainda que peça-chave na solução do problema, dada sua vulnerabilidade nas relações de consumo necessita de informação ambientalmente qualificada para poder exercer de forma plena seu papel de consumidor com consciência e responsabilidade ambiental.

\section{O direito à informação ambientalmente qualificada}

Percebe-se que este é outro requisito fundamental para a prática do consumo consciente: a informação qualificada. Considerando a vulnerabilidade do consumidor, inclusive nos aspectos técnicos que envolvem todo o ciclo de vida e as práticas ambientais das empresas que lhe ofertam produtos e serviços, seu poder de decisão está condicionado diretamente às informações que lhe são prestadas por este.

Conforme estabelece o Código de Defesa do Consumidor, em seu art. $4^{\circ}$ :

Art. $4^{\circ}$ - A Política Nacional das Relações de Consumo tem por objetivo o atendimento das necessidades dos consumidores, o respeito à sua dignidade, saúde e segurança, a proteção de seus interesses econômicos, a melhoria da sua qualidade de vida, bem como a transparência e harmonia das relações de consumo, atendidos os seguintes princípios: I - reconhecimento da vulnerabilidade do consumidor no mercado de consumo;

II - ação governamental no sentido de proteger efetivamente o consumidor: 
a) por iniciativa direta;

b) por incentivos à criação e desenvolvimento de associações representativas;

c) pela presença do Estado no mercado de consumo;

d) pela garantia dos produtos e serviços com padrões adequados de qualidade, segurança, durabilidade e desempenho.

III - harmonização dos interesses dos participantes das relações de consumo e compatibilização da proteção do consumidor com a necessidade de desenvolvimento econômico e tecnológico, de modo a viabilizar os princípios nos quais se funda a ordem econômica (art. 170, da Constituição Federal), sempre com base na boa-fé e equilíbrio nas relações entre consumidores e fornecedores;

IV - educação e informação de fornecedores e consumidores, quanto aos seus direitos e deveres, com vistas à melhoria do mercado de consumo; [...] VIII - estudo constante das modificações do mercado de consumo (grifos nossos).

E de acordo com o art. $6^{\circ}$ :

Art. $6^{\circ}$ São direitos básicos do consumidor:

I - a proteção da vida, saúde e segurança contra os riscos provocados por práticas no fornecimento de produtos e serviços considerados perigosos ou nocivos;

II - a educação e divulgação sobre o consumo adequado dos produtos e serviços, asseguradas a liberdade de escolha e a igualdade nas contratações; III - a informação adequada e clara sobre os diferentes produtos e serviços, com especificação correta de quantidade, características, composição, qualidade e preço, bem como sobre os riscos que apresentem (grifos nossos).

De acordo com o Instituto Akatu, em 14 de fevereiro de 2008 o Governo Federal, por meio do Ministério do Meio Ambiente, criou o Comitê Gestor de Produção e Consumo Sustentável (CGPCS) com a missão de inserir na pauta a discussão sobre as atividades do varejo e do consumo sustentável.

Segundo o diretor do Departamento de Economia e Meio Ambiente do Ministério do Meio Ambiente, responsável pelo CGPCS, Luiz Fernando Krieger Merico, 
o objetivo é transformar nossa economia em uma nova, mais circular e sustentável com menores impactos ambientais. É preciso compatibilizar os processos produtivos (humanos) com a capacidade produtiva da natureza. E isso não é uma escolha. [...] O consumidor pode influenciar o setor produtivo com suas escolhas, induzindo mudanças, embora no Brasil esse poder ainda seja pouco difundido.

Perceba-se que, na edição do Código de Defesa do Consumidor, a preocupação primordial do projeto era de preservar a vida, a saúde, a segurança e a dignidade do consumidor, inclusive por meio da oferta de informação clara e transparente.

Hoje, não há dúvida de que tal dever de informar deve ser lido com uma percepção mais ampla, inclusive nos fatores que transcendem o produto ou serviço em si, principalmente no que se refere às informações ambientais pertinentes ao processo produtivo, hipótese que não foi prevista na edição do Código de Defesa do Consumidor, mas, no atual cenário ambiental, a ampliação de sua leitura faz-se necessária.

E o consumidor, ao ter acesso a informações ambientais dos produtos e serviços que consome, poderá questionar seus fornecedores, exigindo, enquanto consumidor-cidadão, a adoção de práticas ambientalmente seguras e sustentáveis. Com a nova postura e efetiva cobrança do mercado consumidor, que outrora apenas exigia segurança no consumo, hoje se exige uma postura que vai além das qualidades intrínsecas ao produto ou serviço: é preciso que os fornecedores adotem práticas permanentes de responsabilidade socioambiental, não apenas não poluindo, mas agindo de forma pró-ativa, inclusive despoluindo, utilizando matéria-prima reciclada, além de promover a solidariedade e o bem-estar socioambiental enquanto missão corporativa.

O mercado de consumo, ao receber a informação ambientalmente qualificada, certamente será estimulado a adaptar suas práticas e métodos, sob pena de ver seu produto ou serviço ser preterido no mercado em favor de fornecedores ambientalmente e socialmente mais responsáveis. 


\section{O papel das empresas em defesa da sustentabilidade socioambiental}

O papel preponderante das empresas sempre foi o de obtenção de lucros. A ideia inicial da formação de um comércio de produtos e serviços sempre girou em torno das formas pelas quais a lucratividade pode ocorrer.

Com o intuito de sustentar tal política, os lucros são contabilizados pela empresa de forma privada, ou seja, internamente, enquanto os prejuízos e danos acabam por ser socializados; assim se pode dizer sobre a ocorrência da privatização de lucros e socialização de perdas.

Assim não é diferente com o meio ambiente: ao longo de vários anos o ato de empreender depende necessariamente da utilização de recursos naturais (bem de uso comum do povo), implicando a livre disposição de recursos "humanos" (pessoas) e produz, junto com os bens e serviços de consumo geral, resultados materiais sob a forma de gazes, dejetos, compostos químicos, etc., de modo que as consequências do livre agir da pessoa jurídica esbarram no livre agir, na propriedade e nos direitos alheios, não só vistos individualmente, mas muitas vezes alcançando dimensões supraindividuais (BESSA NETTO, 2006, p. 127).

Em contrapartida a este pensamento, nas últimas décadas emerge da sociedade e do próprio mercado a responsabilidade social das empresas. De acordo com o Instituto Ethos, a responsabilidade social deve ser entendida como a forma de gestão que se define pela relação ética e transparente da empresa com todos os públicos com os quais ela se relaciona e pelo estabelecimento de metas empresariais compatíveis com o desenvolvimento sustentável da sociedade, preservando recursos ambientais e culturais para gerações futuras, respeitando a diversidade e promovendo a redução das desigualdades sociais. ${ }^{4}$

A responsabilidade social empresarial incorpora a gestão e abrange toda a cadeia de relacionamentos: funcionários, clientes, fornecedores, investidores, governo, concorrentes, acionistas, meio ambiente e socie-

4 Disponível em: <http://www.ethos.org.br/_Uniethos/Documents/Conclusoes_Akatu.pdf>. Acesso em: 15 jun. 2008, 
dade em geral, devendo acompanhar as expectativas dos consumidores e do próprio mercado.

Respeitar a responsabilidade social diz respeito a agir em conformidade com o direito, com a função social da empresa e com os princípios de direito privado, sempre orientados pelo princípio da boa-fé (BESSA NETTO, 2006, p. 141).

Pode-se dizer que a questão ambiental é incluída nesta ideia de responsabilidade social, por meio de suas múltiplas e variadas relações, que inspiram e fundamentam preceitos morais e normas jurídicas (MILARÉ, 2007, p. 122).

No mundo atual, cada dia maior o número de empresas que se propõe a proceder a implementação de programas de responsabilidade social. Igualmente crescente é o número daquelas que divulgam e documentam os resultados da gestão socialmente responsável em seus balanços, buscando dar maior visibilidade a suas boas práticas.

Nesse sentido, o mercado vislumbra formas de efetivação desta responsabilidade social por meio de boas alternativas que atendam ao clamor do consumo consciente, práticas empresariais que possibilitaram um diferencial mercadológico e que principalmente agregarão valores antes desconhecidos da economia.

Assim, ao estabelecer a gestão da responsabilidade social como estratégia nos negócios, as empresas estarão atendendo às expectativas de uma parcela significativa de seus consumidores, adiantando-se ao que tende a ser uma preocupação cada vez mais ampla no conjunto da sociedade.

O consumidor sustentável procurará empresas que possibilitam este comércio "sem culpa ambiental" ao mesmo tempo em que possibilitará a fidelização de um nicho de mercado sem precedentes. Portanto, pode-se dizer que, a partir de preceitos éticos e de responsabilidade social, as relações de consumo daqui em diante sofrerão mudanças drásticas e passarão pela melhor qualidade de informações aos consumidores, bem como pela ideia das certificações ambientais. 


\section{Certificação ambiental e demais alternativas para o consumo consciente}

O consumo sustentável incorpora, necessariamente, o conceito de produção limpa, incluindo a prevenção à poluição, a conservação de recursos, a ecoeficiência e produtos limpos. Os questionamentos devem mudar de "como podemos produzir um produto de uma maneira que seja ecologicamente responsável?" para "qual é o produto mais sustentável para satisfazer à demanda do público por um serviço?”. Assim se estará aplicando o conceito de sustentabilidade ao lado da demanda da economia, e não apenas ao lado da oferta, da produção (PROGRAMA..., 1998, p. 23).

Aliado a este pensamento, se faz necessária a mudança de mentalidade e atitude do atual consumo, pois o que se observa é que o tempo livre do homem não é despendido em outra coisa senão em consumir, e, por mais assustador que seja, quanto maior é o tempo de que ele dispõe, mais ávidos e insaciáveis são os seus apetites.

Invariavelmente, esses apetites se tornam cada vez mais refinados, de tal forma que o consumo deixa de corresponder às necessidades da vida e, ao contrário, passa a ser relacionado, primordialmente, às coisas supérfluas. Surge, então, o sério perigo de se chegar ao ponto em que absolutamente nenhum objeto do mundo estará a salvo do consumo e da aniquilação a partir do consumo.

Porém, para existir essa mudança de mentalidade, é necessário "desmaterializar" o consumo material, consumo este que é símbolo da realização econômica e do status pessoal. O sucesso é igualado às posses concretas e a padrões de consumo, como se "mais" significasse "melhor".

A ideia de desmaterializar a sociedade implica a mudança de atitudes e de valores humanos tanto quanto modificar tecnologia e produtos. Lidar com estes pontos significa reconhecer o marketing global de massas, que alcança hoje público em todo o mundo através de suas redes, e que vende e perpetua, explícita ou implicitamente, ideias materialistas do que as pessoas devem desejar e comprar (PROGRAMA..., 1998, p. 67).

Em consonância com esse entendimento, deve existir uma política de informações aos produtores e consumidores dos reais custos ambientais 
dos produtos que consumimos (consumo de energia, de matérias-primas, de recursos naturais, geração e descarte de resíduos) (SPINDOLA, 2001, p. 210). Assim surgiria o consumidor sustentável, aquele que, devidamente informado e preocupado com a sustentabilidade do planeta, consegue discernir realmente quais produtos são favoráveis ao meio ambiente e quais apenas alegam sê-lo.

Quando o consumidor possui acesso à informação de qualidade e transparência sobre o processo produtivo das mercadorias, ele avalia seu custo/benefício com mais consciência. Entretanto, a busca pela informação de qualidade esbarra em nomenclaturas e procedimentos desconhecidos da grande maioria dos consumidores. Com esta preocupação e com o intuito de fomentar a população com informações claras, a partir da década de 1990 começou-se a discutir no Brasil a possibilidade de certificação ambiental de produtos.

Busca-se, assim, rótulos ecológicos com a intenção de indicar ao consumidor a melhor opção, quanto ao impacto ambiental, de um produto em relação a outros com a mesma função.

Ocorre que no Brasil a certificação ambiental de produtos surgiu por necessidade de proceder à exportação de produtos. Em razão disso, não houve qualquer iniciativa governamental no sentido de proceder à certificação e fiscalização, ocorrendo que são entidades privadas que realmente realizam a certificação. Assim, deve-se atentar o consumidor ao verificar a apresentação de um selo em um produto, se a certificação é autodeclaratória ou se é realizada por terceiros.

É claro que a certificação realizada por terceiros recebe maior prestígio, tendo em vista que a responsabilidade pelas declarações é compartilhada entre níveis de ação. A existência de um organismo independente possibilita a formulação de critérios e normas que devem ser respeitadas para que só após sejam concedidas as certificações.

No Brasil, a melhor forma de certificação é por meio da normalização da Associação Brasileira de Normas Técnicas (ABNT), credenciada pelo Inmetro e membro do International Organization for Standartization (ISO). Dessa forma, é a ABNT quem controla e certifica as certificadoras da série ISO 14000, que trata sobre questões ambientais. 
Este selo atesta que foram implantados mecanismos de redução de impactos ambientais e principalmente monitoramento constante da análise do ciclo de vida de produtos e serviços. A finalidade do selo não é, meramente, transferir impactos de um estágio do ciclo de vida para outro, mas representar verdadeiro ganho ambiental.

A análise do ciclo de vida deve ser entendida como uma técnica para avaliação dos aspectos ambientais e dos impactos potenciais associados a um produto, compreendendo etapas que vão desde a retirada da natureza das matérias-primas elementares que entram no sistema produtivo (berço) até a disposição do produto final (CHEHEBE, 2002, p. 10).

A análise do ciclo de vida do produto é um dos instrumentosmeios capazes de fornecer os elementos para uma atuação palpável e concreta, ou seja, é uma ferramenta de análise da vida do produto em termos das consequências que causa aos recursos naturais e ao meio ambiente globalmente considerados ao longo do processo de extração, transporte e beneficiamento da matéria-prima (SODRÈ, 1999, p. 25).

Os rótulos ecológicos devem ser regulados pela ISO 14024 Rotulagem Ambiental, que preceitua um guia de certificação com base em análise multicriterial sobre a avaliação do ciclo de vida do produto, análise de observância da legislação ambiental nacional, proteção da vida silvestre, conservação dos recursos hídricos, conservação do solo, observância de legislações trabalhistas, entre outros.

Além da certificação ambiental, cabe ressaltar a existência de outras iniciativas interessantes, como a formação de catálogos de bens sustentáveis, como já vem realizando o Centro de Estudos em Sustentabilidade da Escola de Administração de Empresas de São Paulo, da Fundação Getúlio Vargas, no qual armazena informações sobre produtos e serviços avaliados a partir de critérios de sustentabilidade. Neste catálogo encontram-se informações sobre as características técnicas, aspectos de sustentabilidade, certificações e fornecedores de produtos e serviços. ${ }^{5}$

5 Disponível em: <www.catalogosustentável.com.br>. 
Outro projeto que visa ao despertar da consciência ambiental é o criado pelo Banco Real, no que tange ao recolhimento de pilhas e baterias, com o objetivo de recolher e dar um destino adequado aos produtos que são considerados pela Resolução Conama n. 257/1999 como tóxicos à saúde e ao meio ambiente.

Cabe ressaltar também o trabalho efetuado pela Faber-Castell, que com seu Programa Escolar ${ }^{6}$ procura fornecer educação ambiental por meio de jogos educativos e cartilhas endereçadas às crianças e, por fim, produzindo lápis com $100 \%$ de madeira plantada.

\section{Considerações finais}

A relação entre meio ambiente e consumo possui contradições inerentes a sua existência. Contudo, não se pode vislumbrar o mundo, com o atual modo de produção vigente, sem a existência da produção e do consumo. Os padrões de consumo mundiais chegaram a um patamar em que os ricos querem cada vez mais consumir e os pobres que não consomem buscam esta possibilidade.

Em contrapartida, a sustentabilidade do planeta encontra-se ameaçada em virtude desta persecução. Já não há mais espaço para tanto desperdício, futilidade e consumo exacerbado. Deve-se pensar em políticas públicas eficazes e iniciativas privadas que constituam um estímulo, principalmente, à conscientização da população diante do atual problema.

Nesse sentido, vigorosa arma que deve ser utilizada como prérequisito à prática do consumo consciente é a educação ambiental, que tem por premissa o desenvolvimento sustentável. Inerente a esta educação ambiental encontra-se a prestação de informações claras, corretas, transparentes e ambientalmente qualificadas ao consumidor. Deve-se melhor

6 Disponível em: <http://www.ecomunidade.com.br/projetos-ambientais/programa-de-educacaoambiental/>. Acesso em: 19 jun. 2008. 
elaborar os rótulos dos produtos, bem como buscar produtos que sejam certificados por instituições responsáveis socioambientalmente.

Contudo, a resposta não deve surgir apenas e tão somente da iniciativa privada, mas também do Estado, por meio da contínua implementação de políticas públicas, inclusive de educação ambiental, concomitantemente da iniciativa privada, a partir da adoção de princípios fundamentados no desenvolvimento socioambiental sustentável, e do consumidor, com papel importante no exercício do consumo consciente, privilegiando empresas ambientalmente responsáveis, que serão identificadas a partir da oferta de informação ambientalmente qualificada (selos, certificações, catálogos).

\section{Referências}

BESSA NETTO, F. L. B. Responsabilidade social das empresas: práticas sociais e regulação jurídica. Rio de Janeiro: Lumen Juris, 2006.

BRASIL. Ministério do Meio Ambiente - MMA. Lei n. 9.795, de 27 de abril de 1999. Dispõe sobre a Educação Ambiental, Institui a Política Nacional de Educação Ambiental e dá outras providências. Diário Oficial [da] República Federativa do Brasil, Ministério do Meio Ambiente, Brasília, DF, 27 de abr. 1999. Disponível em: <http://www.mma.gov.br/sitio/index.php?ido=conteudo. monta\&idEstrutura=20\&idConteudo=967 > Acesso em: 20 jan. 2010.

CHEHeBE, J. R. B. Análise do ciclo de vida do produto. Rio de Janeiro: Qualitymark, 2002.

INSTITUTO AKATU. Descobrindo o consumidor consciente: uma nova visão da realidade brasileira. Disponível em: <http://www.ethos.org.br/_Uniethos/ Documents/Conclusoes_Akatu .pdf >. Acesso em: 19 jun. 2008.

MILARÉ, É. Direito do ambiente: doutrina, prática, jurisprudência e glossário. São Paulo: Revista dos Tribunais, 2007. 
MINISTÉRIO do Meio Ambiente centra esforços no Consumo Sustentável. Disponível em: <http://www.akatu.com.br/central/noticias/2008/ministerio-do-meioambienta-centra-esforcos-no-consumo-sustentavel〉. Acesso em: 14 jun. 2008.

PROGRAMA das Nações Unidas para o Desenvolvimento. Consumers Internacional. Consumo sustentável. 2. ed. São Paulo: Secretaria do Meio Ambiente: IDEC, 1998.

RESPONSABILIDADE Social das empresas: percepção do consumidor brasileiro. Instituto Ethos. Disponível em: <http://www.uniethos.org.br/_Uniethos/ Documents/consumidor_2002.pdf >. Acesso em: 17 jun. 2008.

SODRÉ, M. G. Padrões de consumo e meio ambiente. Revista de Direito do Consumidor, São Paulo, n. 31, p. 25-35, jul./set. 1999.

SPINDOLA, A L S. Consumo sustentável, o alto custo ambiental dos produtos que consumimos. Revista de Direito Ambiental, v. 6, n. 24, p. 200-216, out./ dez. 2001.

VARGAS, L. A. Educação ambiental: a base para uma ação político/transformadora na sociedade. Revista eletrônica do Mestrado em Educação Ambiental, v. 15, jul./dez. 2005. Disponível em: <http://www.remea.furg.br/edicoes/vol15/ art06.pdf >. Acesso em: $20 \mathrm{dez} .2009$.

Recebido: 13/02/2010

Received: 02/13/2010

Aprovado: 22/02/2010

Approved: 02/22/2010 